\title{
SYNTHESIS AND STRUCTURAL PROPERTIES OF COBALT SUBSTITUTED ZINC FERRITE-LEAD TITANATE COMPOSITE
}

\author{
1Gawali S. R., ${ }^{2}$ Moharkar P. R., ${ }^{2}$ Lengule S.B., ${ }^{3}$ Kherani R. R. and \\ ${ }^{4}$ Rewatkar K. G.
}

${ }^{1}$ Dr. Ambedkar College, Chandrapur (M.S) India

${ }^{2}$ Arts, Commerce and Science College, Chandrapur (M.S) India

${ }^{3}$ Shree Shivaji College, Rajura (M.S) India

${ }^{4}$ Dr. Ambedkar College, Nagpur (M.S) India

Email: sanjaygawali500@gmail.com

\begin{abstract}
The series of samples of composite of Cobalt substituted zinc ferrite and lead titanate with composition (y) $\mathrm{PbTiO}_{3}-(1-\mathrm{x}) \mathrm{ZnFeCoO}_{4}$ ( $\mathrm{x}=0$ to 0.50 and $\mathrm{y}=1$ ) were synthesized by standard ceramic method. X-ray powder diffraction (XRD) patterns of all prepared samples confirms the cubic spinel structure in ferrite phase and tetragonal perovskite structure in ferroelectric phase of the composites. The lattice parameters a and $\mathrm{c}$ for both the phases in these composites vary slightly with the composition. The $\mathrm{X}$ - ray density and porosity of the composite materials are in the moderate range as compared to that of ferrite and ferroelectric phase. Hence the ferrites-ferroelectric composites find the applications in microwave devices.
\end{abstract}

Keywords:Ferrite-ferroelectric composite, Structural property, X ray density, Porosity, Ceramic method

\section{Introduction:}

The ferrite-ferroelectric composite materials have generated a great deal of interest both because of their magnetic and electric properties and their potential for application in electronic devices [1]. The coupling between the electric polarization and intrinsic magnetization of these materials allows for the observation of the magnetoelectric effect: An applied external electric field causes the magnetic dipoles to reorient, resulting in a net shift in the material's magnetization direction. Such magnetic control would allow for magnetic switching using an applied electric field, an effect which could be applied towards improving memory devices and electronic systems.

Several researchers have already attempted to fabricate composites of ferroelectric/ferromagnetic nanostructures [2]. In most cases, however, the proposed methods involve chemical etching or ionbeam milling. These methods damage the substrate, oftentimes rendering it conductive and hindering its magnetoelectric capabilities.

The ferrite - ferroelectric composite were prepared by ceramic method [3] or by eutectic method [4] or by sol gel method [5].
The ceramic method for the preparation of composites was preferred compared to other methods because ceramic method is easier and cheaper. Further the preparation of composite offer certain advantages such as choice of mole ratio of constituent phases, free choice of sintering temperature etc [6]. The properties of composites depend of the purity of the starting material, mixing, sintering temperature and the time of sintering. Also the microstructural factors like grain size, defect concentration, porosity considerably affect the properties of composites. Hence during the preparation various factors are controlled to have a good quality of composites.

In present research, the samples of cobalt substituted zinc ferrite, lead titanate and their composite are synthesized by standard ceramic method. The structural properties of the prepared samples have been investigated.

\section{Experimental: \\ Sample preparations}

Cobalt substituted Zinc ferrite samples are prepared by standard ceramic method using A.R. grade oxides in stoichiometric proportion. The chemical formula of the ferrite sample under investigation is $\mathrm{ZnFeCoO}_{4}$. The raw materials used for preparation of ferrite are A.R. grade oxides 
such as Zinc oxide ( $\mathrm{ZnO})$, Cobalt Carbonate $\left(\mathrm{CoCO}_{3}\right)$ and Ferric oxide $\left(\mathrm{Fe}_{2} \mathrm{O}_{3}\right)$. The oxides were weighed in required molar proportion using mono pan balance. The required weighed oxides were mixed thoroughly in an agate with acetone medium. This mixture is then allowed to dry up and transferred to a clean and dry crucible.

Lead titanate ferroelectric samples are also prepared by standard ceramic method using A.R. grade oxides in stoichiometric proportions. The chemical formula under the investigation is $\mathrm{PbTiO}_{3}$. The raw materials used for the preparation of ferroelectric are A.R. grade oxides such as, Titanium oxide $\left(\mathrm{TiO}_{2}\right)$ and Lead oxide $(\mathrm{PbO})$. The ferroelectric samples are also prepared in the same way as that of the ferrite samples

Ferrite- ferroelectric composites were prepared by standard ceramic method the constituent phases were presintered at $750^{\circ} \mathrm{C}$ for $4 \mathrm{~h}$ separately. After presintering, these were grounds to fine powder. The composites of Cobalt were synthesized by dispersing 100, 75 and 50 mole \% of ferrite phase $\left(\mathrm{ZnCoFeO}_{4}\right)$ into matrix of ferroelectric phase $\left(\mathrm{PbTiO}_{3}\right)$ and labeled as $\mathrm{KR}_{1}, \mathrm{KR}_{2}$ and $\mathrm{KR}_{3}$ for ZCOF-PTO composites respectively. They were mixed thoroughly and at $950^{\circ} \mathrm{C}$ for $4 \mathrm{~h}$ and once again these composites were mixed thoroughly and pressed into pallets of diameter $13 \mathrm{~mm}$ and thickness 4 $\mathrm{mm}$. The palletized samples were sintered at $1200^{\circ} \mathrm{C}$ for $6 \mathrm{~h}$ and slow cooled.

\section{Characterization}

Phase analysis of grinded, calcined and sintered samples was carried out using a Xray diffractometer (Model PW-1830, Philips, Netherland) with copper $\mathrm{Cu}-\mathrm{Ka}$ radiation $(\boldsymbol{\lambda}=1.54060 \AA)$ operated at $45 \mathrm{kV}$ voltage and $40 \mathrm{~mA}$ current.

Lead Oxide is volatile above $750^{\circ} \mathrm{C}$, however the Critical temperature is still debatable. The weight loss at temperatures $\geq 1050^{\circ} \mathrm{C}$ may be due to the volatilization of $\mathrm{PbO}$ content as reported in a number of previous studies $[7,8]$.

\section{Results and discussion:}

\section{Ferrite Phase Analysis}

The XRD patterns obtained for $\mathrm{ZnCoFeO}_{4}$ is shown in Fig. 1. The dvalues have been found out for cubic lattice from lattice parameters values for the indexed planes.

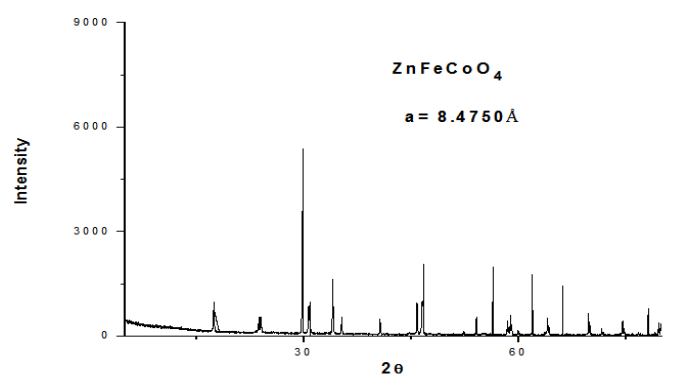

Fig. 1: X- ray diffraction pattern of $\mathrm{ZnFeCoO}_{4}$

The observed $d$ values and calculated values are in good agreement with the spinel structure. No irregular peaks are observed in the XRD pattern which reveals a single phase formation of ferrite. In both the system (311) peak appears to be more intense as expected. The observed and calculated $d$ values for different planes are represented in table 1 .

Table-1: XRD data of $\mathrm{ZnFeCoO}_{4}$ (ferrite) $\mathrm{a}=8.4750 \AA$

\begin{tabular}{|c|c|c|c|c|}
\hline $\begin{array}{c}\text { Angle } \\
\mathbf{2 \theta} \\
\mathbf{D e g}\end{array}$ & $\begin{array}{c}\mathbf{d}_{\text {obs }} \\
(\mathbf{A})\end{array}$ & $\begin{array}{c}\mathbf{d}_{\text {cal }} \\
(\mathbf{\AA} \mathbf{)}\end{array}$ & $\mathbf{I}_{\mathbf{I}} \mathbf{\mathbf { I } _ { \mathbf { 0 } }}$ & $\begin{array}{c}\text { Plane } \\
\text { (hk1) }\end{array}$ \\
\hline 18.115 & 4.8930 & 4.876 & 26.8 & $(111)$ \\
\hline 29.793 & 2.9963 & 2.9943 & 47 & $(220)$ \\
\hline 35.089 & 2.5553 & 2.5553 & 100 & $(311)$ \\
\hline 36.704 & 2.4465 & 2.4459 & 86 & $(222)$ \\
\hline 42.638 & 2.1187 & 2.1184 & 3.6 & $(400)$ \\
\hline 46.680 & 1.9443 & 1.9443 & 40 & $(331)$ \\
\hline 54.060 & 1.6950 & 1.6949 & 10.7 & $(430)$ \\
\hline 56.365 & 1.6310 & 1.6300 & 59 & $(511)$ \\
\hline 61.882 & 1.4982 & 1.4982 & 56 & $(440)$ \\
\hline 62.950 & 1.4753 & 1.4673 & 10 & $(522)$ \\
\hline 66.096 & 1.4125 & 1.4125 & 28 & $(442)$ \\
\hline 73.169 & 1.2924 & 1.2923 & 32 & $(533)$ \\
\hline 78.057 & 1.2232 & 1.2212 & 15 & $(444)$ \\
\hline
\end{tabular}

\section{Ferroelectric Phase Analysis}

The XRD pattern of $\mathrm{PbTiO}_{3}$ sample at various temperatures are shown in Fig. 2, it was evident from the pattern that an annealing temperature of $500^{\circ} \mathrm{C}$ is necessary for the emergence of characteristic peaks. It is clearly evident that the characteristic peaks of tetragonal $\mathrm{PbTiO}_{3}$ start to emerge at the annealing temperature of about $400^{\circ} \mathrm{C}$. The final single phase was achieved at the sintering temperature $1060^{\circ} \mathrm{C}$. The XRD pattern 
recorded for $\mathrm{PbTiO}_{3}$ sample is shown in Fig. 2. One can see that the sample is essentially in single phase form within the instrumental error. All the observed peaks could be indexed to $\mathrm{P} 4 \mathrm{~mm}$ space group with tetragonal symmetry. The cell parameters are found to be $\mathrm{a}=\mathrm{b}=3.8987 \AA$ and $\mathrm{c}=$ $4.1380 \AA$. These values are found to be comparable to those of Jona and Shirane [9]. The unit cell volume is found to be $62.896\left(\AA^{3}\right)$. The axial ratio c/a is found to be 1.0614 which is less than that of earlier reported value 1.063 [10]. The low axial value shows that the material is more compact and structure is more stable. Hence we could prepare the material with less axial ratio by following the solid state route.

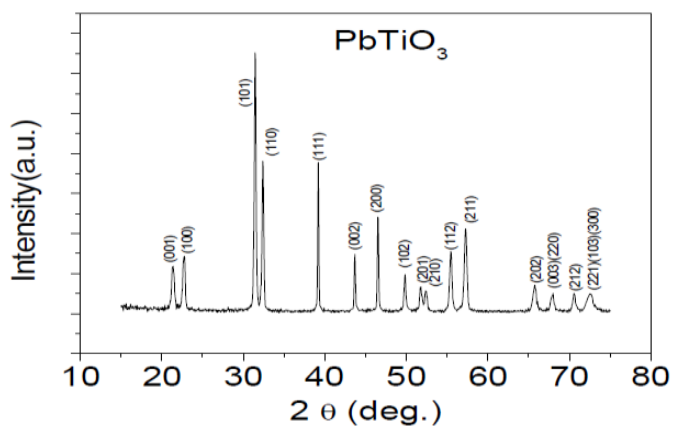

Fig.-2: X- diffraction pattern of $\mathrm{PbTiO}_{3}$ compound at annealed at temperature $1060^{\circ} \mathrm{C}$

\section{Composite Analysis}

The XRD pattern of the composites are shown in Figs. 3 to 5 . The lattice parameters a and c, X -ray density and porosity of the ferrite, ferroelectric and composite materials were calculated using standard formulae and they are enumerated in table 2. It is clear from the data the densities of ferroelectric material is higher than its counterpart (ferrites). The porosity of the synthesized compounds are between 10 to $20 \%$.

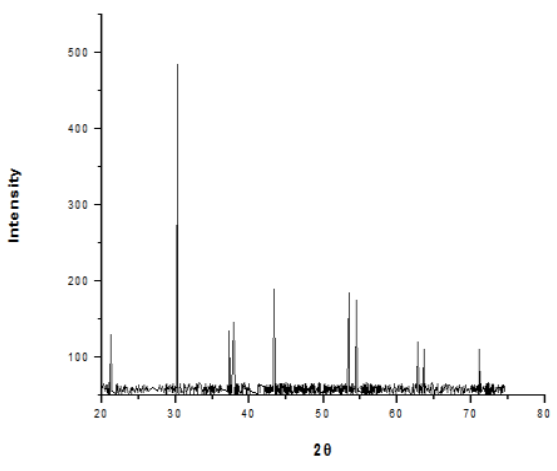

Fig. 3: $\mathrm{X}-$ ray diffraction pattern of (y) $\mathrm{PbTiO}_{3}-(1-\mathrm{x}) \mathrm{ZnCoO}_{4}$ where $\mathrm{x}=0, \mathrm{y}=1$

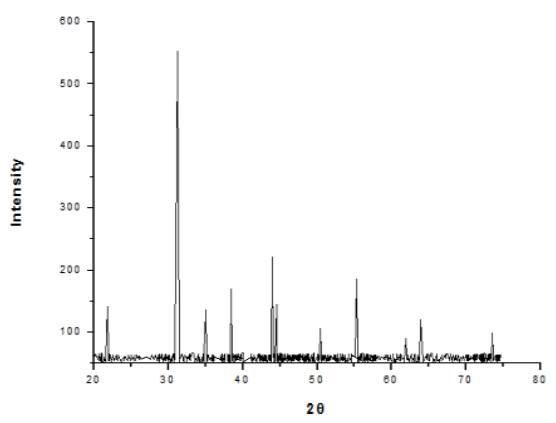

Fig. 4: $\mathrm{X}$ - ray diffraction pattern of $(\mathrm{y})$ $\mathrm{PbTiO}_{3}-(1-\mathrm{x}) \mathrm{ZnCoO}_{4}$ where $\mathrm{x}=0.25, \mathrm{y}=1$

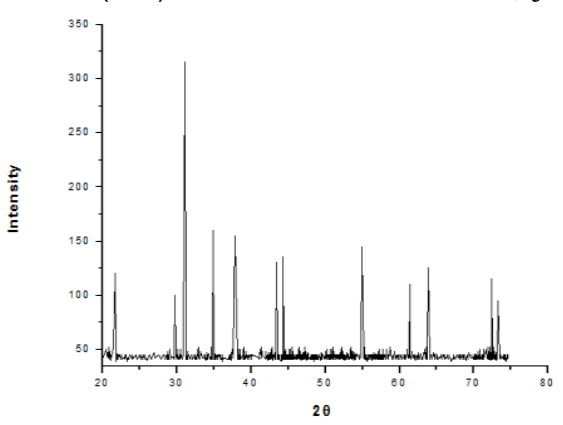

Fig. 5: X- ray diffraction pattern of $(\mathrm{y})$ $\mathrm{PbTiO}_{3}-(1-\mathrm{x}) \mathrm{ZnCoO}_{4}$ where $\mathrm{x}=0.50, \mathrm{y}=1$

Table 2: Lattice parameters a and c, X- ray density and porosity of Ferrite, ferroelectric and composite samples

\begin{tabular}{|c|c|c|c|c|c|}
\hline $\begin{array}{l}\text { Compositi } \\
\text { on }\end{array}$ & $\begin{array}{c}\mathbf{a} \\
\text { (这) }\end{array}$ & $\begin{array}{l}\text { c } \\
\text { (Å) }\end{array}$ & $\begin{array}{c}\text { Molecular } \\
\text { Weight in } \\
\text { (gm) }\end{array}$ & \begin{tabular}{|c|} 
X-ray \\
density \\
$\mathrm{dx}$ \\
$\left(\mathrm{gm} / \mathrm{cm}^{3}\right)$
\end{tabular} & $\begin{array}{c}\text { Porosity } \\
\text { P (\%) }\end{array}$ \\
\hline $\begin{array}{l}\text { ZnFeCo } \\
\mathrm{O}_{4}\end{array}$ & 8.4750 & -- & 244.476 & 5.337 & 14.521 \\
\hline $\mathrm{PbTiO}_{3}$ & $\begin{array}{l}a=b=3.898 \\
7\end{array}$ & 4.1380 & 303.089 & 8.090 & 5.908 \\
\hline $\mathbf{K R}_{1}$ & 3.88631 & 4.1700 & 547.565 & 6.575 & 13.327 \\
\hline $\mathbf{K R}_{\mathbf{2}}$ & 3.9169 & 3.9460 & 486.446 & 6.773 & 12.870 \\
\hline $\mathbf{K R}_{3}$ & 3.8537 & 4.0321 & 425.327 & 7.045 & 11.756 \\
\hline
\end{tabular}


The lattice parameters and the $\mathrm{c} / \mathrm{a}$ ratio of the constituent phases match well to that reported in the literature [11,12]. The occurrence of peaks with specific indices characteristics of spinel and perovskite structure confirms cubic spinel structure in ferrite phase and tetragonal perovskite structure in ferroelectric phase of the composites. There are no structural changes observed for both the phases in the composites. The lattice parameters a and $\mathrm{c}$ for both the phases in these composites slightly vary with the composition.

\section{Conclusion:}

The cobalt substituted zinc ferrites, lead titanate (Ferroelectric) and their composite samples were synthesized by the standard ceramic method. The XRD data of composite samples have confirm the formation of cubic spinel structure in ferrite phase and tetragonal perovskite structure in ferroelectric phase of the composites.

Acknowledgement:

Authors are grateful to Principal, Dr.Ambedkar College, Deekshabhoomi, Nagpur for giving us permission to use laboratory facility.

\section{References:}

Ryu J., Priya S., Uchino K., Kim H. E. and Viehland D., J. Korean Ceram. Soc., 39, 813 (2002).

Calvani P., Capizzi M., Donato F., Lupi S., Maselli P. and Peschiaroli D.,Phys. Rev. B 47, 8917, (1993).

Gelyasin A. E. and Laletin V. M., , Izvestija Akademii Nauk SSSR, vol. 24, pp. 20672069, (1988).

Boomgaard van Den J. Terrell J., Born R. A. J. and Giller H. F. J. I.,J. Mat.Sci., 9, 1705 (1974).

Suryanarayana S.v., Bull. Mater.Sci. 17 (7) 1259-1270 (1994).

Toshihika Sato, Chinji Kuroda and Minora Sato,Ferrite Proc. Inter. Conf. Japan, 72(1970).

Kim S., Cheol J. M., Cheol H. S., J Am Ceram Soc. 82(2), 289-296 (1999).

Forrester J. S., Zobec J. S., Phelan D., Kisi E. H., J Solid Stat Chem".177, 35533559 (2004).

Jona F. and Shirane G., "Ferroelectric crystals", Dover publications, Inc., New York, (1962).

Shin Y. H., Cooper V. R., Grinberg I. and Rappe A. M.,Phys. Rev. B 71, 054104 (2005).

Goodenough J. B. and Loeb A.L., Phy.Rev. 98, 391, (1955).

Narendrababu S., Seong G., Leszek Malkinski, J. App. Phy.109, 07D911 (2011). 